\title{
The New Role of the Private Sector in Community Development: A Case Study in Artisanal Fishery Communities in Thailand
}

\author{
Nawat Kamnoonwatana ${ }^{1}$, Orada Wongamphaiwit ${ }^{1}$, Atip Asvanund ${ }^{1}$
}

\begin{abstract}
Private sector's role in community development is often seen as a supporting organization with its own interests. Generally, a company chooses to support a particular community according to the company's strategic topic. This top-down approach benefits the company in many ways including effective operations and communications. However, the effectiveness on sustainable development of communities is still questionable. As each strategic topic is heavily influenced by the company's reasoning, this approach often lacks in dimensions, has narrow focus, and therefore disconnects with the community real needs. This results in little contributions to the sustainability of the communities. This proposal proposes a different approach through a case study with two artisanal fishery communities. With this new approach, the company acted as a bridging organization working closely with the communities together with other stakeholders to truly understand their needs. The company, then, facilitated them in designing and implementing their own sustainable solutions. This requires changes in the company operations as well as acquiring new knowledge for its outreach team. The findings demonstrated a successful case of community development towards selfsustainable resource management. The analysis of these findings helps the company to strike a balance between "company-centric" and "community-centric" approach in the future.
\end{abstract}

\section{Introduction}

The private sector role in operating its business in a way that is ethical, as well as, contributing to social, economic and environmental development at the same time is typically known as Corporate Social Responsibility (CSR). It is often viewed by the public as well as the private sector themselves as an unsuccessful and unsustainable approach of developing local communities and creating financial 1 benefits to the firms. Over three decades, alarm about climate change, health pandemics, economic crisis and income inequality is increasing apace with global temperatures. The private sector, nowadays, realized that CSR has become more importance than being voluntary and philanthropy annual activities. On the contrary, firm must embrace the benefits of integrating sustainability into their business models, budgets, practices and value chains through the concept of Creating Shared Value. This dynamic role can be defined by recognition and collaboration between multiple stakeholders i.e. employees, suppliers, national laws, international guidelines, customers, and public (local or international). These dynamic and various definitions and expectations are one of the key challenges for business with all sizes and all industries.

In the recent years, the United Nations (UN) released the Sustainable Development Goals (SDGs) which are signposts to illustrate the link between economic, social and 
environmental issues. To achieve the SDGs, it is well recognized that social and environment issues cannot be solved by the public sector itself. The private sector is considered as another important player in this field as it remarkably plays a role in driving national economy. In terms of involving in sustainable development, the private sector can contribute (1) sustainable production processes and technologies, (2) sustainable economic growth, (3) decent job creation and many more.

Community Development (CD) is one of the topics that has been described as one of the areas where private sector can contribute in terms of business and CSR activities inevitably interact with communities including its own employees, local community or community at a larger scale. In a broad sense, $\mathrm{CD}$ is an effort made by an institution or more in order to solve community problems. It is important to note that by UN definition (Mayo, 1999), CD must be carried by the community itself and with minimal help from external organizations.

This proposal examines an alternative role in which a company could take part in community development. The company's efforts are based on the UN definition where the ultimate goal of company's intervention is community's empowerment. Thai artisanal fishing communities were chosen in this study because they are one of the vulnerable groups of people whose livelihoods have been impacted by the declination of marine resources.

\section{Methodology}

\subsection{Proposed Role}

Private sector's role in rural community development is often seen as an external funding or supporting organization with its own interests. Generally speaking, a company chooses to support a particular community under a particular issue according to its strategic CSR goal and activity. For example, a company establishes its strategic topic to be improving the well-being of rural communities by focusing in providing access to medical services. When such company chooses which community to work with, it evaluates many aspects this includes locations, their needs in health care service, relationships with the company, relationships with NGO and governments, cultural difference, social and political structure, etc. Nevertheless, the chosen communities, finally, need to align with the company's strategy i.e. medical services.

On the other hand, social workers in general do not have such strict constraint. Inarguably, those from civil society organizations or academics have their own interests according to their organizations' purpose and therefore must also work towards these goals. However when comparing to a company's CSR effort, these organizations is able to work with more freedom and flexibility. This allow them to work under variety of topics that address community's true needs.

\subsubsection{Characteristics}

In the light of aforementioned difference and the company's own interest in focusing on sustainable community development, a more flexible approach was initiated since the past year in several places in Thailand. Specifically speaking, the new approach of a private sector towards community development described in this paper follows 
similar path with those social workers and pay full attention to the community needs rather than company's own constraint. The four characteristics of such approach is depicted in Figure 1.
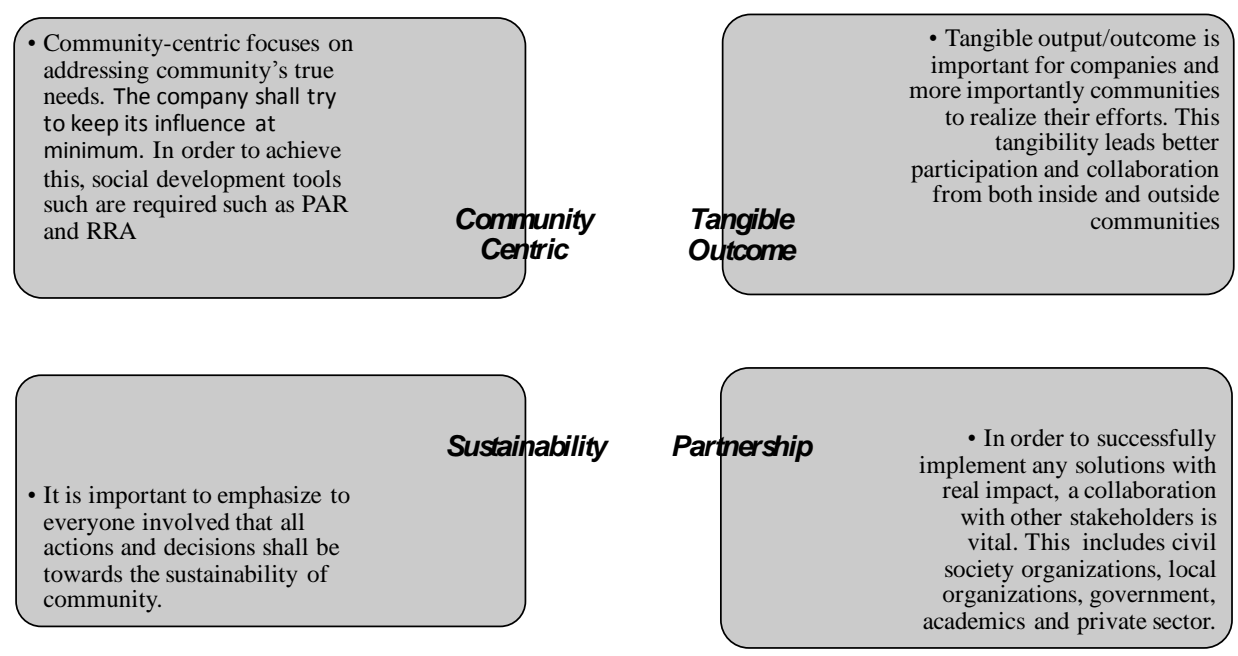

Figure 1 New Approach's Characteristics

\subsubsection{Supporting Drivers}

To support the four characteristics, there are a number of enabling drivers in which the company has adopted. This includes:

\subsubsection{Dedicated Field Team}

A dedicated team is essential in carrying out all engagement activities with the communities. Moreover, they are the core factor to a successful project. The composition of the team was diverse in personal competency and demography. This includes people who have background in laws, social science, and natural resource management. The aim of this is to have an interdisciplinary team as suggested in Rapid Rural Appraisal (RRA) which is one of the popular set of tools for analyzing a rural community. The field team's engagement with the community is based on the Participatory Action Research (PAR) as this type of research allows the field team to fully understand the community while at the same time was able to draw tangible outputs. This simply supports all characteristics described earlier.

\subsubsection{Flexible Management and Operation}

To effectively support the field team, a well-balanced top-down and bottom-up management approach was required. The new community-centric approach requires that the management and operations to be adaptive and responsive. This is because each community has its own problems within its own context. An activity or a solution in one place cannot be entirely duplicate to other communities. Therefore, the management and operations must be resilience to this diverse environment. 


\subsubsection{Knowledge}

Field team as well as the central management must equip themselves with extra set of skills and knowledge which are essential to meet all above mentioned requirements. These are community development, regulatory, marine resources and soft skills as summarized in

Table 1 below.

Table 1: Knowledge and Skills

\begin{tabular}{|l|l|}
\hline Discipline & Topics \\
\hline $\begin{array}{l}\text { Community } \\
\text { Development }\end{array}$ & $\begin{array}{l}\text { Sustainable Livelihood Framework } \\
\text { Community-led Resource Management or co-management } \\
\text { Engagement and development tools such as Snowball Sampling, RRA, } \\
\text { PRA and PAR }\end{array}$ \\
\hline $\begin{array}{l}\text { Marine Resource } \\
\text { Management }\end{array}$ & $\begin{array}{l}\text { Ecosystem Approach Fisheries Management (EAFM) } \\
\text { Marine science and technology }\end{array}$ \\
\hline $\begin{array}{l}\text { Related Regulatory and } \\
\text { Laws }\end{array}$ & $\begin{array}{l}\text { Department of Fisheries, Ministry of Agriculture and Cooperatives } \\
\text { Department of Marine and Coastal Resources, Ministry of Natural } \\
\text { Resources and Environment } \\
\text { Marine Department, Ministry of Transportation }\end{array}$ \\
\hline $\begin{array}{l}\text { Management and } \\
\text { Communication Skills }\end{array}$ & $\begin{array}{l}\text { Public speaking } \\
\text { Negotiation } \\
\text { Conflict management } \\
\text { Project management }\end{array}$ \\
\hline
\end{tabular}

\subsection{Participatory Action Research}

As mentioned earlier, Participatory Action Research was used as a tool for field team to approach, engage and work with the communities. The research was carried out with a close collaboration with local academics to ensuring credible results. The analysis of research is based on the following three principles: 1) Strategic Roles of Field Team 2) Sustainable Livelihood Framework and 3) Bridging Organization

\subsubsection{Strategic Role of Field Team}

Strategic role of the field team was defined prior any engagement work was carried out and it is essential for everyone in the team to understand their roles. It is important to stress out that their role is not typical CSR activities that concentrate on pre-identified company's interests i.e. company-centric approach. The field team is also not social a development officer from government, NGOs nor fulltime researchers. Their role is therefore unique in balancing the two ends and can be summarized as follows:

1) The field team shall work together with the communities. They shall understand the communities from inside out and able to facilitate, encourage and empower the communities.

2) The field team understand company's strategic goals and policy. They shall embed these goals into all activities and communications with the communities.

3) The field team acts as a Bridging Organization and must exploit company's strength as much as possible. 


\subsubsection{Sustainable Livelihood Framework}

Sustainable Livelihood approaches as stated (Krantz, 2001) were considered. These include three approaches from UNDP, CARE and DFID. The DFID approach (Ashley, 1999) was selected as the basis framework for the field team's community development work. This is because unlike the other two, DFID principle emphasizes more on the analysis of the community rather than proposing steps or procedure for projects. This means it leaves room for flexibility for the implementers. Furthermore, DFID not only provides community-level analysis it also offers the analysis at a bigger picture such as policies and institutional factors.

At its core, DFID provide the following principles: People-centered, Participatory, Dynamic environment, Macro-micro links, Partnership and Sustainable. It is important to note that the four characters of the proposed approach discussed earlier and DFID principles are well aligned. Five types of livelihood assets or capitals that must be captured in order to effectively analyze the community's situation and draw out meaningful livelihood strategies that can help elevate their livelihood. These five assets are human capital, social capital, natural capital, financial capital and physical capital. These assets were captured during the research and its analysis were done with full participation with communities.

\subsubsection{Bridging Organization}

To aid the above strategic role of the field team, the concept of Bridging Organization (Berkes, 2009) was used to explain "how" should those strategic roles can be achieved. Bridging Organization is a crucial part in the co-management of local marine resources. Since the co-management requires effective co-production of knowledge so that power and responsibility are appropriately distributed among all stakeholders, this requires an intermediary who is the catalyst as well as a facilitator that build healthy linkages between different parties who possess different governance, knowledge and resources.

\section{Results}

An interdisciplinary team (i.e. the field team) was formed specifically for engaging closely with artisanal fishing communities. The team composed of people from different backgrounds including coastal resource management, business administration, and sales. A dedicated manager was assigned to manage this particular team and help link up the company's strategy and policy with the field team.

\subsection{Thai Artisanal Fishing Communities}

Marine fisheries contribute significantly on Thailand's economy ensuring its food security and self-sufficiency as indicated in the Marine Fisheries Management Plan of Thailand (Department of Fisheries, 2015). Thousands of lives are dependent on marine fisheries including fisherman, and those who work in various value chains that are involved with marine fisheries. The national plan further suggests, based on a survey 
in 2015, that the number of artisanal fishing vessels ${ }^{1}$ were about $78 \%$ of all fishing vessels in Thailand while their catch only contribute to only $11 \%$ of the total catch in 2014. According to the data from the National Statistical Office Thailand, there are 53,343 households who live along the 23 coastal provinces in Thailand.

The current status of Thailand's fishery resources is worrisome. According to the national trawl surveys that are carried out annually by the Department of Fisheries (DOF). The CPUE (catch per unit effort) values, that are used to represent the amount of fishing resources, have dramatically declined since 1961. Precisely speaking, the CPUE value that represents catch in the Gulf of Thailand in 2014 was only 9\% of CPUE value that was measured back in 1961. Moreover, Thailand is currently harvesting more than it should i.e. beyond its maximum sustainable yield (MSY).

From aforementioned facts, the declining of marine resources in Thailand is enormous and it has been impacting the livelihood of artisanal fisher folks as they are heavily relying on marine resources. Together with the fact that artisanal fisher folks often lack in livelihood security for example there are issues such as land rights, fishers' legal status, and financial accessibility, it is therefore not an overstatement to say that artisanal fisher folks in Thailand are considered as one of the vulnerable groups. Many of their communities are now facing severe social and economic problems. Some are even facing the collapse of its identity and traditional culture.

There were two artisanal fishing communities in Songkhla province, the southern coast of Thailand, where the team worked closely with. First community was located in Rawa Sub-District and the second one was located in Sanamchai Sub-District. Both of these communities are rather small in terms of vessels and households. They were struggling with the decline of coastal resources. For example, the artisanal fishermen in Rawa community were able to catch blue swimming crabs at the rate of 30-40 kilograms per catch effort in 2007 but the number has dropped to 5-6 kilograms in 2017. Even though, the market price of these blue swimming crabs has indeed gone up, this does not compensate the loss of quantity and hence the overall income declined along with the marine resources. This insecure income inevitably impacts their traditional pride and culture as less pupils were going to continue their fishing legacy and moved in to towns or worked at factories, conventional stores and worse became involved with illegal activities.

It is important to mention that these two communities did not abandoned their values and cultures altogether. They initiated marine resource improvement programs with the help from external sources particularly from local NGOs and local government bodies such as the Southern Gulf Fisheries Research and Development Center (SMDEC) which is under the Department of Fisheries and the local branch of Office of the Non-formal and Informal Education which is under the Ministry of Education. These programs were particularly involved with the concept based on local-run burry crab hatchery system i.e. Crab Bank (Jöhl, 2013) that aims at enhancing the stocks of blue swimming crabs in the coastal areas. However, up until 2017, these initiatives were not successfully

1 Artisanal fishing vessels are grouped into two groups: (1) Small artisanal fishing vessels are those with engine power less than 180 horsepower and less than 5 gross tonnages; and (2) Large artisanal fishing vessels are those with engine power between 180-220 horsepower and capacity between 5 to 10 gross tonnages. 
implemented nor self-sufficient in the sense that the two communities are relying heavily on external funding.

\subsection{Community Engagement}

The field team started to engage Sanamchai since November 2016 and Rawa since January 2017. Over the range of one year, engagement activities can be summarized into four phases as shown in the

Table 2.

Table 2: Research Phase

\begin{tabular}{|l|l|l|}
\hline Phase & Main activities & Output/Outcome \\
\hline $\begin{array}{l}\text { 1. Preliminary data } \\
\text { collection }\end{array}$ & $\begin{array}{l}\text { Approach communities } \\
\text { Short-term CSR activities } \\
\text { Gathering general information about } \\
\text { the communities through semi- } \\
\text { structure interview and observations. }\end{array}$ & $\begin{array}{l}\text { Team increase their } \\
\text { understanding about the } \\
\text { communities } \\
\text { Building trust and relationship } \\
\text { Workable data for next steps }\end{array}$ \\
\hline $\begin{array}{l}\text { 2. Acquiring } \\
\text { knowledge }\end{array}$ & $\begin{array}{l}\text { Link to experts from academics and } \\
\text { government through meetings and } \\
\text { small workshops } \\
\text { Visit other success communities and } \\
\text { learn from case studies } \\
\text { Research methodology and } \\
\text { participatory approach }\end{array}$ & $\begin{array}{l}\text { Communities and team learn } \\
\text { more about development } \\
\text { methodology } \\
\text { Communities understand about } \\
\text { PAR and teams' objectives }\end{array}$ \\
\hline $\begin{array}{l}\text { 3. Livelihood } \\
\text { strategy }\end{array}$ & $\begin{array}{l}\text { Five assets and SWOT analysis } \\
\text { Research topic identification } \\
\text { Designing approach and plan out } \\
\text { activities } \\
\text { Roles and responsibilities }\end{array}$ & $\begin{array}{l}\text { Analysis of community's assets } \\
\text { Research question and } \\
\text { approach identification } \\
\text { Implementation plan }\end{array}$ \\
\hline $\begin{array}{l}\text { 4. Implementation } \\
\text { and Evaluation }\end{array}$ & $\begin{array}{l}\text { Carry out activities as plan } \\
\text { Monitoring and analyze for continuous } \\
\text { improvement i.e. modify plan if needed } \\
\text { Project assessment }\end{array}$ & $\begin{array}{l}\text { Data collection system } \\
\text { Success factors and challenges } \\
\text { Future plan }\end{array}$ \\
\hline
\end{tabular}

\subsection{Community Empowerment}

Though Sanamchai and Rawa artisanal fishing communities are rather close in proximity (about 20 kilometers distance), their contexts especially in terms of social capital were different.

Artisanal fishing community in Sanamchai sub-district is no stranger to the idea of "People Organization". Its leader shown his understanding in the importance of a strong community's organization. In 2010, he was one of the pioneer who helped organizing the cooperative for artisanal fishermen in Songkhla province. In the same year, the community also initiated a community-based saving group that aimed at helping fellow fishermen particularly in household's financial access and saving discipline. From 2011, onwards they have been actively engaged in coastal resources enhancement activities including fish enhancing devices (FED), beach cleanup and berried crab hatchery system that aims at enhancing blue swimming crab population (Crab Bank). However, the crab hatchery system was not successful. 
Artisanal fishing community in Rawa sub-district have been experiencing the declination of marine and coastal resources for the past ten years. This declination became prominent in the last five years. This community has no experience in any communitybased activities nor setting up formal community-based organization.

With different backgrounds and contexts, activities and livelihood strategies are different as shown in

Table 3.

Table 3: Livelihood Strategy

\begin{tabular}{|c|c|c|c|}
\hline & Local Context & Analysis & Livelihood Strategy \\
\hline & \begin{tabular}{|l|} 
Existing community- \\
based organization \\
Strong linkage with \\
local CSOs \\
Marine resources \\
severely damaged \\
Experienced with \\
unsuccessful initiatives
\end{tabular} & $\begin{array}{l}\text { Strength: Experienced } \\
\text { personnel (human capital) with } \\
\text { strong networks } \\
\text { Weakness: doubtful members } \\
\text { and severe resources that } \\
\text { prevent community-based } \\
\text { Crabs Bank (or any other } \\
\text { marine animals) opportunities }\end{array}$ & $\begin{array}{l}\text { Conservation Areas with } \\
\text { community rules that govern how } \\
\text { local resources can be used. The } \\
\text { aims at } 1 \text { ) conserving marine } \\
\text { resources 2) strengthen co- } \\
\text { management efforts }\end{array}$ \\
\hline & $\begin{array}{l}\text { No experience with } \\
\text { community-based } \\
\text { organization } \\
\text { Marine resources } \\
\text { declined but not as } \\
\text { severe as Sanamchai }\end{array}$ & $\begin{array}{l}\text { Strength: Open minded and } \\
\text { willing to accept new } \\
\text { knowledge } \\
\text { Weakness: Lack of experience } \\
\text { and require participation }\end{array}$ & $\begin{array}{l}\text { Crab Bank that aims at increasing } \\
\text { community's participation, } \\
\text { community's awareness on } \\
\text { resource management and crabs } \\
\text { population }\end{array}$ \\
\hline
\end{tabular}

\subsubsection{Sanamchai Community}

As mentioned earlier that Sanamchai initiated a "crab bank" that aims at enhancing crabs stock in 2011. The crab bank model adopted in Sanamchai was based on Donation model (described in the Crab Banks: a Literature Review (Jöhl, 2013)) such that the gravid female crabs were donated to the bank where they were carefully put into small rearing tanks. The zoeas of these newly spawn crabs were released back to the sea. The female crabs were then return to the owners.

When the field team engaged with the community in 2016, it was found that there was lack of participation from fellow community's members. It was reported that very little to none gravid female crabs were donated to the bank. It was speculated by the communities that the high price of crabs has put negative incentives to their members who were more likely to sell their crabs to the market instead of donating them to the bank. Furthermore, as the model of their crab bank does not incorporate any income to support their operation and maintenance. It was extremely difficult to maintain crab bank. Their crab bank was basically finally abandoned and left with only empty house and tanks.

During the initial phase of engagement, the field team facilitated the learning process (i.e. capacity building) of the community in a number of areas that were within community's interests. These were community's saving group, coastal conservation area and community's rules, and crab bank management and operation. They visited a number of artisanal fishing communities who have experience and successful in those areas. The 
field team then organized a number of meetings where the community members analyzed and drew conclusions on what have they learnt from each of the visit and how would these case studies be applied to their own.

After several meetings and workshops, the team facilitated the livelihood strategy designing process with the community based on the Five assets and SWOT analysis. The community agreed that designated coastal conservation areas where agreeable local rules are used to govern marine resources within the area. This was due to the fact that, the result from analysis showed that the very reason that bank crab and other conservation activities did not success was because there was no supportive mechanism. That is, any efforts in enhancing marine resources such as increasing crab stocks (releasing baby crabs) or introducing environmental friendly fish enhancing devices (FED) were not effective as once crabs were releasing back to the sea they have little chance surviving and reproducing. Similarly, as FEDs were installed in area that were not governed by any rules and participation from fishermen in the area, they were used as fishing tools instead of conserving them.

Therefore, a supportive mechanism for effective conservation is required. That is a proper designated conservation area should be established. The process of this establishment shall encourage full participation from local fishermen and stakeholders in the area. These participations will enable a recognition by all stakeholders especially those government bodies who have authority over such coastal area. Furthermore, they should agree on "how" the conservation area should be governed as well. This include rules and enforcement.

\subsubsection{Rawa Community}

On the other hand, while artisanal fishermen in Rawa is experiencing similar declination of coastal resources, they were very new in organizing any conservation activities and efforts.

The team engaged the community early January 2017 and learnt that the community's leader was interested in implementing crab bank within the community based on the introduction of the concept by the local branch of Office of the Non-formal and Informal Education. At the time they were particularly interested in financial support from private sector rather any other kind of support. The company was introduced to this community by an officer the Non-formal and Informal Education which is under the Ministry of Education.

During the capacity building phase, since the community members had shown particular interest in implementing crab banks, they were therefore exposed to the management of crab bank and related conservation area. They visited several successful communities. Followed by a number of meetings and workshops, the field team facilitated the livelihood strategy designing process with the community based on the Five assets and SWOT analysis. The crab bank model, implementation plan, management, data collection and assessment was designed by the community with the help of field team.

The funding from the company together with the funding from the Southern Gulf Fisheries Research and Development Center (SMDEC) enabled the crab bank project to move forward. The crab bank was a hybrid model in which the participated fishermen have the choice to either donate or sell the gravid female crabs to the bank. This allow 
crab bank to have flexibility in gaining participation and have income to support the operation of crab bank at the same time. Later in July 2017, the community's efforts received an official recognition by the DOF by winning an award for being the best community (within the area of five provinces) for their initiative in community-based fisheries management.

Furthermore, the community has initiated the process towards their conservation zone together with local rules. However, this is still in its early stage as no official recognition from authority was received and that not all stakeholders were included in the designing process.

\section{Discussion and Analysis}

\subsection{Field Team Empowerment}

After one-year engagement with the two artisanal fishing communities, field team as well as central management learnt three crucial facts that are required for community development work:

(1) Earning trust is vital and as a company this may be more difficult than CSOs, academics or even government staff. This is especially true if community has negative view about the company.

(2) Each community is unique. We cannot and shall not copy-and-paste solutions nor assumptions.

(3) Community organizations and community engagement principles and tools are important and should be learnt very quickly.

\subsection{Bridging Organization}

As a bridging organization, the company helped link "scientific knowledge" with "local wisdom" and "local institutes" with "government bodies". The factor that encourages the very existence of bridging organization in artisanal fishing community development in Thailand is the known fact that there is an immediate need to establish the co-ownership on marine and coastal resource. This is fundamental for inclusive development and co-management towards sustainable livelihoods and marine resources. The above factor clearly identifies the role of a bridging organization i.e. gathering of different stakeholders, creating the environment that encourage a single set of shared visions and goals by building trust and respects that are based on equality and justice, and finally stakeholders' harmony roles and responsibilities must be clearly identified and executed.

Base on the field team's experience, its role as a bridging organization has been successful this was due to the fact that all stakeholders had common realization and goal towards coastal and marine resources. They all (including government bodies) realized that marine resources were heavily degraded to the point that they all must do something to rectify this. More importantly, they all realized that in order to address this issue they all need to work together but there was no appropriate stage nor opportunities for them to work together. The team effort as a bridging organization filled in this gap and therefore experienced good participations from all parties. 


\subsection{The New Role}

As suggested in the journal on CSR roles in community development (ISMAIL, 2009), common roles of CSR in community development involve transferring knowledge, strengthening relationship, and gathering data. It is clear that the proposed approach in the paper is unique in its own way. On surface, the proposed approach shares several aspects with other previous approaches such as they involved building healthy relationship with communities and transferring own knowledge and technology. However, for the proposed approach, these overlap subjects are simply a tool (or a means) and not the goal (or an end).

The main difference is the perspective of which the company took or choose to tackle social issues in community development. The new role suggests that while the company should exploit its knowledge and leverage its strength as much as possible, this exploitation shall not burden the community's sustainable livelihood strategy and the company shall facilitate such livelihood strategy as much as possible through the role of bridging organization.

This new role of private sector requires new type of investments and as a result the company who adopted this role needs to innovatively create how to benefit from this. These new investments do not only cover social development activities, they also cover investments for human capitals, organizational changes, new processes and network development. In order to benefit from the new role, the company must understand and measure the success or return on investment in a total different view. For example, with traditional CSR role in community development, it is easy to monitor progress, measure success, and most importantly to communicate and advertise to public. However, the new role will leave a company with various topics and social issues that are dependent on communities' sustainable livelihood strategies. The same thinking that the company used to do to monitoring progress, measuring output/outcome, and communication is no longer apply.

\section{Conclusion}

The new role of private sector in rural community development is proposed in this paper. The approach was experimented in two artisanal fishing communities in Thailand and shown promising results. The role is based on the concept of Bridging Organization and Participatory Action Research. That is the company facilitated the two communities by means of linking them with other organizations, external knowledge as well as extending their networks that are essential for achieving their sustainable livelihood strategies. The company also helped in the process of developing livelihood strategies based on the DFID livelihood framework and its five assets. Furthermore, PAR provided the team with community engagement tools, collection tools and analysis. It also supports the inexperienced field team with proven research methodology and principle. Results shown promising community development cases in which one of the two communities had in fact received a community-based fisheries management from the department of fisheries. Finally, this new role introduces new investments especially in social and human capitals and therefore require innovative ways that the company must consider in order to fully benefit from their efforts. 


\section{References}

Adam A. Kowalski, L. D. (2015). The role of bridging organizations in environmental management: examining social networks in working groups. Ecology and Society, 20(2), Art. 6.

Ashley, C. a. (1999). Sustainable liveliboods: Lessons from early experience. London: DFID.

Berkes, F. (2009). Evolution of co-management: Role of knowledge generation, bridging organizations and social learning. Journal of Environmental Management, 90(5), 1692-1702.

Department of Fisheries. (2015). Marine fisheries management plan of Thailand: a national policy for marine fisheries management (2015-2019). Bangkok: Ministry of Agriculture and Cooperatives.

Ismail, M. (2009). Corporate Social Responsibility and Its Roles in Community Development: An International Perspective. The Journal of International Social Research, 2/9, 199-209.

Jöhl, A. (2013). Crab Banks: a Literature Review. International union for conservation of nature. Bangkok: IUCN Southeast Asia Group.

Krantz, L. (2001). The Sustainable Livelihood Approach to Poverty Reduction: Introduction. Swedish International Development Cooperation Agency, Division for Policy and Socio-Economic Analysis. Stockholm: Swedish International Development Cooperation Agency.

Mayo, S. B. (1999). Culture, community development and representation. Oxford University Press And Community Development Journal, 191-204. 